Check for updates

Cite this: J. Mater. Chem. A, 2021, 9 , 17242

Received 20th May 2021 Accepted 15th July 2021

DOI: $10.1039 / d 1 t a 04288 b$

rsc.li/materials-a

\section{Acetylene-linked conjugated polymers for sacrificial photocatalytic hydrogen evolution from water $\dagger$}

\author{
Lunjie Liu, ${ }^{a}$ Michał A. Kochman, ${ }^{b}$ Yongjie Xu, ${ }^{a}$ Martijn A. Zwijnenburg, (D)*b \\ Andrew I. Cooper (iD *a and Reiner Sebastian Sprick (iD *ac
}

\begin{abstract}
Conjugated organic polymers have shown potential as photocatalysts for hydrogen production by water splitting. Taking advantage of a high throughput screening workflow, two series of acetylene-linked copolymers were prepared and studied for their potential as photocatalysts for sacrificial hydrogen production from water. It was found that a triethynylbenzene-based polymer with a dibenzo $[b, d]$ thiophene sulfone linker (TE11) had the highest performance in terms of hydrogen evolution rate under visible illumination in the presence of a sacrificial hole-scavenger. Synthetically elaborating the triethynylbenzene linker in TE11 by changing the core and by introducing nitrogen, the resulting hydrogen evolution rate was further increased by a factor of nearly two.
\end{abstract}

\section{Introduction}

As a result of rapid human development and rising energy demand, the search for new sustainable energy supplies has become an important global challenge for society. Hydrogen has advantages compared to traditional fossil-fuels, owing to its higher energy density and clean combustion. Over the past three decades, photocatalytic and photoelectrochemical (PEC) hydrogen production from water under sunlight irradiation have been studied in an attempt to solve the environmental problems associated with fossil fuels. ${ }^{1-4}$

Significant efforts have been made in this area since 1972 with the experiments reported by Fujishima and Honda using $\mathrm{TiO}_{2}$ as the anode material in a PEC cell for water splitting. ${ }^{5} \mathrm{So}$ far, the search for photocatalytic water splitting materials has mainly focused around using inorganic semiconductors. While semiconducting organic materials were studied as early as three decades ago, ${ }^{6-8}$ they received little attention until 2009, when graphitic carbon nitride was reported as a photocatalyst for photocatalytic hydrogen production in the presence of a holescavenger. ${ }^{9}$ After this, many organic photocatalysts have shown potential as photocatalysts for hydrogen production from water, such as linear conjugated polymers, ${ }^{6,10-13}$ conjugated

${ }^{a}$ Department of Chemistry and Materials Innovation Factory, University of Liverpool, 51 Oxford Street, Liverpool L7 3NY, UK. E-mail: aicooper@liverpool.ac.uk

${ }^{b}$ Department of Chemistry, University College London, 20 Gordon Street, London WC1H OAJ, UK. E-mail: m.zwijnenburg@ucl.ac.uk

${ }^{c}$ Department of Pure and Applied Chemistry, University of Strathclyde, Thomas Graham Building, 295 Cathedral Street, Glasgow G1 1XL, UK. E-mail: sebastian. sprick@strath.ac.uk

$\dagger$ Electronic supplementary information (ESI) available. See DOI: $10.1039 / \mathrm{d} 1 \mathrm{ta} 04288 \mathrm{~b}$ microporous polymers (CMPs), ${ }^{12-15}$ covalent organic frameworks (COFs), ${ }^{16-20}$ hydrogen-bonded organic frameworks $(\mathrm{HOFs})^{21}$ and covalent triazine-based frameworks (CTFs). ${ }^{22-26}$ Recently, organic materials have also been reported to perform water oxidation ${ }^{24,27}$ and even overall water splitting. ${ }^{28-30}$ Due to the diversity of monomers and different polymerization routes, many different polymer photocatalysts have been synthesized, ${ }^{31}$ but their performance as photocatalysts for hydrogen evolution from water is still lower than for the best inorganic semiconductors. ${ }^{32}$

In previous work, a large series of conjugated polymers was synthesized by Suzuki-Miyaura polycondensation and tested as hydrogen production photocatalysts using a high-throughput workflow, showing that the screening allows for the accelerated discovery of high performance photocatalysts. ${ }^{11-13,17}$ Acetylene-linked polymer photocatalysts and photoelectrode materials have been used for water splitting or pollutants degradation under visible light illumination with good results. ${ }^{33-37}$ For example, acetylene-linked thiophene polymers on $\mathrm{Cu}$ foam supports exhibited high cathodic photocurrents, demonstrating the potential of acetylene-bridged materials. ${ }^{33}$ Similarly, 1,4-diethynylbenzene-based linear conjugated polymers were found to be more photocatalytically active compared with 1,4-benzene-based linear conjugated polymers, and introducing the ethynyl group into their backbones can enhance visible light absorption, photocurrent intensity, and hydrogen production activity. ${ }^{34}$

Motivated by these studies, we synthesized a new library of acetylene-linked conjugated polymers based on 1,3,5-triethynylbenzene (TE, see Fig. 1) and 1,4-diethynylbenzene (DE) via a palladium-catalysed Sonogashira cross-coupling reaction. The photocatalytic hydrogen evolution activities of these polymers 


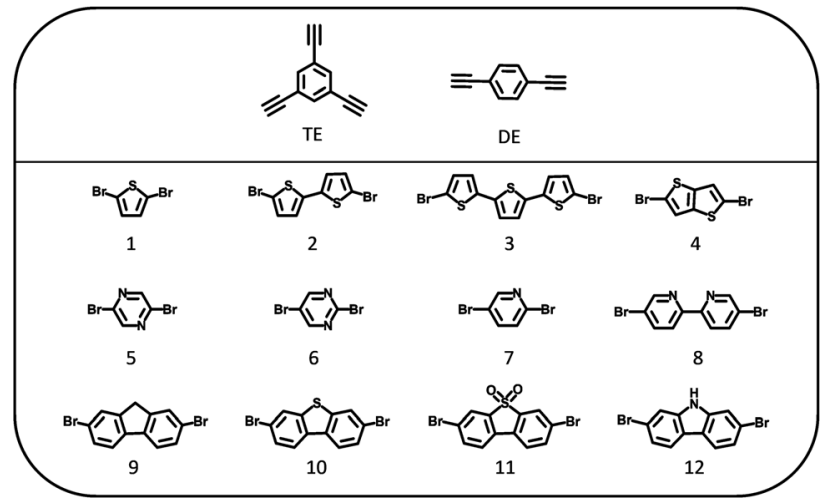

Fig. 1 Structures of the 1,3,5-triethynylbenzene (TE), 1,4-diethynylbenzene (DE) and dibromo monomers (1-12) used to synthesize the polymer photocatalysts.

in the presence of triethylamine (TEA) as a hole scavenger and platinum as a co-catalyst were tested using our high-throughput workflow. Among this library of polymers, TE11 was the bestperforming polymer photocatalyst with the hydrogen evolution rate of $1080 \mu \mathrm{mol} \mathrm{g}{ }^{-1} \mathrm{~h}^{-1}$ under visible illumination $(\lambda>$ $420 \mathrm{~nm}$ ). Based on this, we further optimized the structure by changing the linker length and using a triazine containing core to give TEBN11. The hydrogen evolution rate of this material was improved to $1894 \mu \mathrm{mol} \mathrm{g} \mathrm{g}^{-1} \mathrm{~h}^{-1}$ with an EQE of $2.7 \%$ at $420 \mathrm{~nm}$.

\section{Results and discussion}

\section{Synthesis and characterisation}

All polymers were synthesized by Pd-catalyzed SonogashiraHagihara polycondensation of 1,3,5-triethynylbenzene or 1,4diethynylbenzene with a range of dibromo-functionalized monomer linkers (1-12; Fig. 1) to give the corresponding TE-n or DE-n polymer photocatalysts (whereby $\mathrm{n}$ is the corresponding dibromo monomer linker). The polymers were classified into the three subsets: sulfur-heterocycles (1-4), nitrogenheterocycles (5-8), and planar heterofluorenes (9-12).

All materials were characterized by microanalysis and Fourier transform infrared (FTIR) spectroscopy (Fig. S1-S3†). All FTIR spectra show a peak around $2190 \mathrm{~cm}^{-1}$ that can be assigned to the $\mathrm{C} \equiv \mathrm{C}$ stretching modes of the acetylene linker present in all materials. ${ }^{38,39}$ In addition, we found that the crosslinked TE polymer networks were amorphous while the linear DE polymers were semi-crystalline, as evident by their powder X-ray diffraction patterns (Fig. S4-S6†). Scanning electron microscopy images (Fig. S7-S9†) showed variable morphologies for the polymers; most TE polymers tended to form spherical nano aggregates, while the linear DE polymers consisted mainly of flakes or blocks. Thermogravimetric measurements under $\mathrm{N}_{2}$ showed that all polymers were thermally stable to around $250{ }^{\circ} \mathrm{C}$ under $\mathrm{N}_{2}$ (Fig. S10-S12 $\dagger$ ). The apparent Brunauer-Emmett-Teller $\left(\mathrm{SA}_{\mathrm{BET}}\right)$ surface areas were estimated using nitrogen adsorption isotherms at $77 \mathrm{~K}$ and up to 1 bar (Fig. S13-S15 and Table S1 $\dagger$ ). The BET surface areas of all linear DE polymers fell below $60 \mathrm{~m}^{2} \mathrm{~g}^{-1}$, while the TE polymers showed variable surface areas: 5 polymers had surface areas ranging from $150-600 \mathrm{~m}^{2} \mathrm{~g}^{-1}$ that denoted a degree of porosity, with other samples being essentially non-porous $\left(\mathrm{SA}_{\mathrm{BET}}<30 \mathrm{~m}^{2} \mathrm{~g}^{-1}\right)$.

UV-visible absorption spectra were measured in the solid state to study optical properties of the materials (Fig. S16-S18 $\dagger$ ). All polymers had absorption onsets in the visible part of the solar spectrum and most TE polymers had small red shift in their onset compared to their corresponding DE polymers. The optical gaps of the polymers (Table S2 $\uparrow$ ) range from $1.85 \mathrm{eV}$ for TE4 to $2.52 \mathrm{eV}$ for TE8. Time-resolved single photon counting experiments were performed to study the lifetime of the excited state (Fig. S19-S42 and Table S3†). The weighted average fluorescence lifetimes of TE and DE polymers varied from 0.3 ns to $2.6 \mathrm{~ns}$, with most materials having lifetimes shorter than $1 \mathrm{~ns}$.

Contact angle measurements with water were performed to study the wetting behaviour of the polymers (Fig. S43-S44 and Table S4 $\dagger$ ). Polymers TE4, TE6, TE7 and TE11 absorbed water and swelled, while the TE8 polymer showed the highest water contact angle $\left(115.7^{\circ}\right)$. TE5 had the lowest contact angle of $59.5^{\circ}$; the contact angles of the DE polymers ranged from $75^{\circ}$ to $95^{\circ}$.

The dispersibility of all polymers in TEA/methanol $(\mathrm{MeOH}) /$ water mixtures was determined by measuring the transmittance of the resulting photocatalyst dispersions (Table S5†), where lower transmission means better dispersibility (that is, less particle settling). The dispersibility of TE5 particles was the highest with a transmittance value of just $0.5 \%$, while the transmittance of TE12 and DE10 were approximately $80 \%$, indicating poor dispersibility in the reaction mixture, which could also be observed by eye. Particle size distributions of polymers were measured by static light scattering experiments (Fig. S45-S47 and Table S6 ${ }^{\dagger}$ ). The DE polymers were found to have smaller average particle sizes (8.9-18.5 $\mu \mathrm{m})$ compared to the respective TE polymers $(20.6-86.1 \mu \mathrm{m})$.

In addition, their electron affinity (EA) and ionization potential (IP) were predicted based on density functional theory (Fig. 2 and Table S7†). EA governs the driving force for proton reduction, while IP governs the driving force for water oxidation (or TEA oxidation in this case), which are often approximated in the literature (though not here) by the energy of the LUMO (lowest unoccupied molecular orbital) and HOMO (highest occupied molecular orbital), respectively. ${ }^{13,25,40}$ The EA values of all polymers are more negative than the proton reduction potential at $\mathrm{pH} 12.3$ (the experimentally measured $\mathrm{pH}$ of the TEA/MeOH/water mixture), which means they all should be able to reduce protons when illuminated. All polymers should also be able drive the overall oxidation of TEA to diethylamine and acetaldehyde. However, for a number of the polymers, e.g., TE3/ 4 and DE3/4, the one-hole oxidation of TEA, the first step in the overall oxidation, is predicted to be endergonic, suggesting that this step might give rise to a thermodynamic barrier.

To rapidly screen the photocatalytic activity of all polymers, we used the same high-throughput workflow that we reported previously (Table S8†). ${ }^{\mathbf{1 3 2 5}}$ TEA was used as a hole scavenger and platinum was added by photodeposition from $\mathrm{H}_{2} \mathrm{PtCl}_{6}$ (3 wt\% based on polymer) as the cocatalyst for hydrogen evolution. 


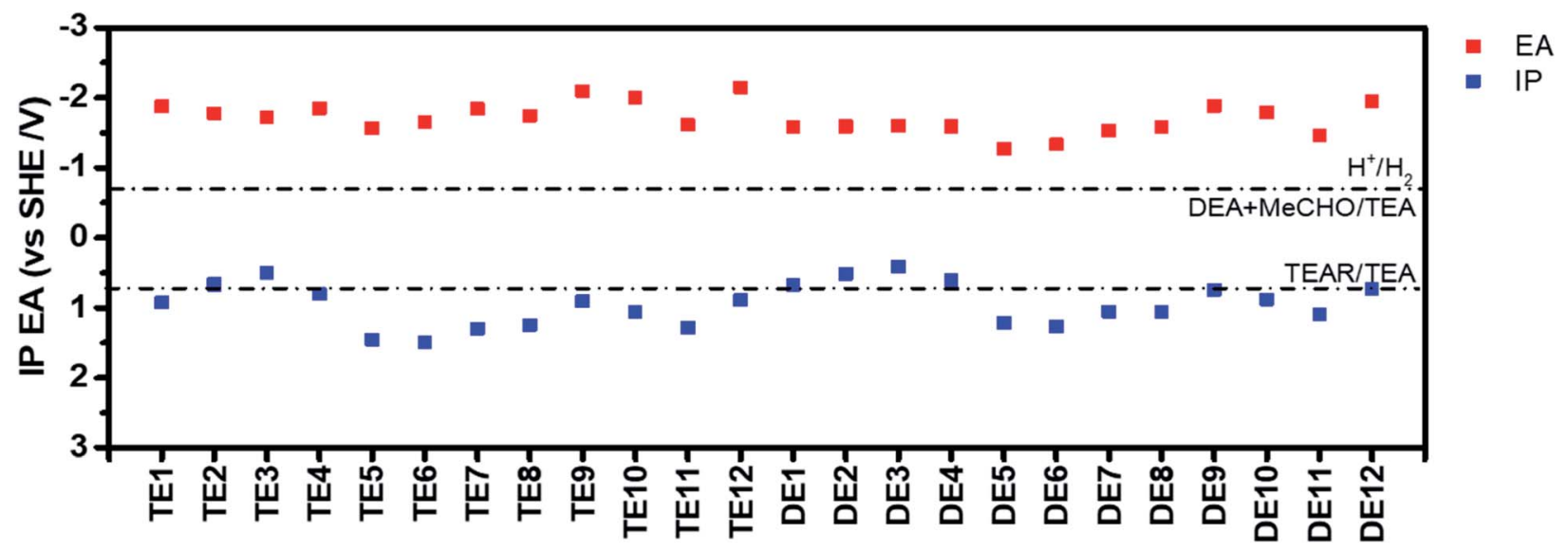

Fig. 2 Predicted IP and EA potentials of the different polymers. Solution half reactions are shown for $\mathrm{pH} 12.3$, the measured $\mathrm{pH}$ of the TEA/ $\mathrm{MeOH} /$ water mixture (MeCHO-acetaldehyde; TEAR-deprotonated TEA radical).

After $2 \mathrm{~h}$ illumination under simulated solar light (1 sun), the TE11 photocatalyst showed the highest hydrogen production rate (Table S8†) by some margin of $1811.0 \mu \mathrm{mol} \mathrm{g}^{-1} \mathrm{~h}^{-1}$. The correlation of the hydrogen evolution rates and factors were plotted to study the relationship between the performance of the polymers and their properties (Fig. S49-S56†), it seems once more that there is no single property that dominates the photocatalytic activity, as found in previous studies. ${ }^{\mathbf{1 3 , 2 5}}$

\section{Structural modification of TE11}

In an attempt to further improve the photocatalytic activity of the best-performing polymer, TE11, we modified the linker by using TEB instead of TE, which bears additional phenylenes and therefore extends the conjugation length of the linker. We also explored TEBN, which is the triazine analogue of TEB (Fig. 3a).

TEB11 and TEBN11 were characterised by FT-IR (Fig. S57†), and characteristic bands at $1160 \mathrm{~cm}^{-1}$ and $2190 \mathrm{~cm}^{-1}$ were attributed to the $\mathrm{S}=\mathrm{O}$ stretching vibration and $\mathrm{C} \equiv \mathrm{C}$ stretching modes, respectively. ${ }^{39}$ The presence of alkyne bonds was furthermore confirmed by solid-state ${ }^{13} \mathrm{C}$ cross-polarization magic angle spinning (CP-MAS) NMR spectra (Fig. S58 $\dagger$ ) showing a characteristic peak at approximately $90 \mathrm{ppm}$ while Raman spectra showed a feature at $2210 \mathrm{~cm}^{-1}$ indicative of carbon-carbon triple bonds (Fig. S59†). ${ }^{38}$ PXRD patterns of all three materials showed that these materials were amorphous (Fig. S60 $\dagger$ ). Their morphologies varied: TE11 comprised porous flake-like structures while TEB11 was composed of non-uniform nanospheres; TEBN11 consisted mainly of large, fused aggregates (Fig. S61†). The absorption onset of TEB11 was found to be similar to TE11, while TEBN11 showed a slight red-shift (Fig. 4a). In line with this observation, TEBN11 was also predicted to have a narrower fundamental gap than TE11 (Fig. 3b). Compared with TE11, the photoluminescence emission spectra of TEB11 and TEBN11 showed a red shift (Fig. S62 $\dagger$ ), which was consistent with the absorption spectrum. X-ray photoelectron spectra showed a shift in the high-resolution peaks of $\mathrm{C} 1 \mathrm{~s}, \mathrm{O} 1 \mathrm{~s}$ and $S$ 2p after modification of TE11 (Fig. S63 $\dagger$ ), which could be attributed to the changes of electronic properties induced by extending the linker length and introduction of nitrogen into the benzene-ring. ${ }^{41}$ TEB11 and TEBN11 also showed increased fluorescence lifetime (Fig. 4b and Table S9†) and improved thermal stability compared with TE11 (Fig. S64†); by contrast, the materials were found to be more hydrophobic against water (Fig. S65 and Table S10 $†$ ), but in mixtures of TEA/MeOH/water, thanks to the wettability of organic solvents, the dispersibility was improved (Table S10†). Finally, average particle sizes were

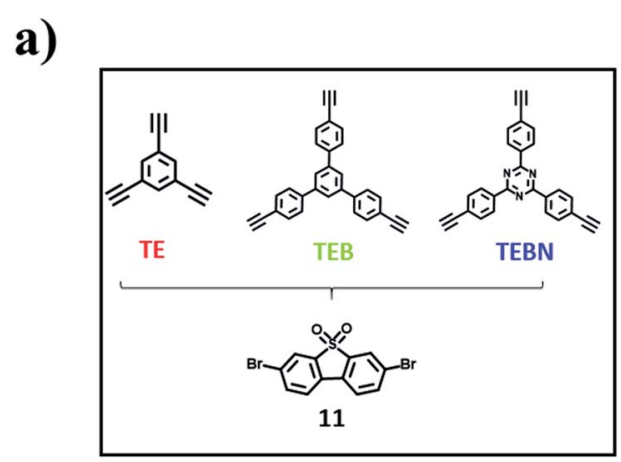

b)

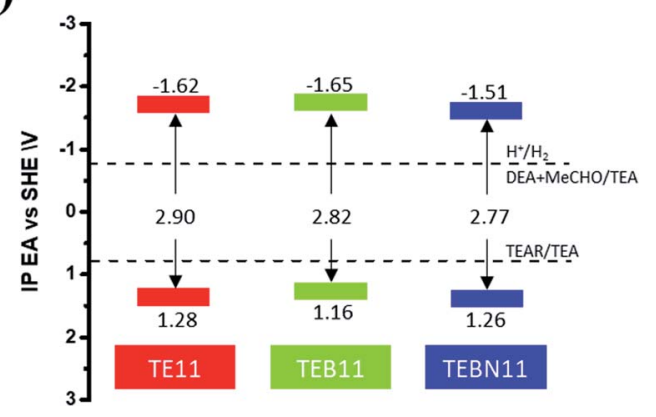

Fig. 3 (a) Chemical structures of expanded TE analogues; (b) predicted EA and IP positions for the resulting copolymers. Solution half reactions are shown for $\mathrm{pH} 12.3$, the measured $\mathrm{pH}$ of the TEA/MeOH/ water mixture (MeCHO-acetaldehyde; TEAR-deprotonated TEA radical). 
a)

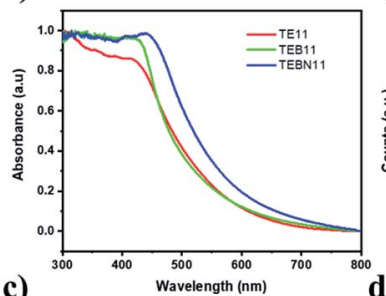

b)
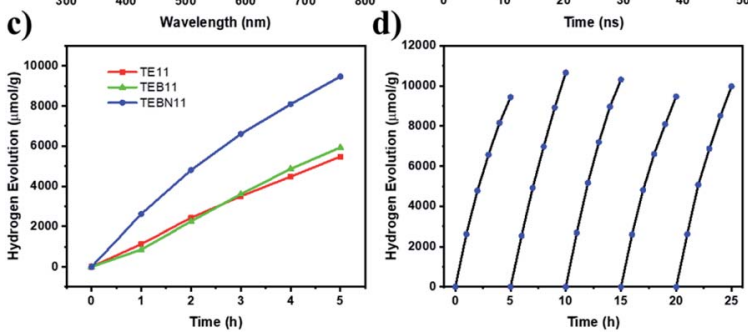

Fig. 4 (a) Solid state UV-vis spectra for copolymers; (b) fluorescence lifetime of TE11, TEB11, and TEBN11 measured in ethanol suspensions; (c) photocatalytic HER performance of TE11, TEB11 and TEBN11; (d) repeat photocatalysis runs for TEBN11 under visible light (300 W Xe light source with $\lambda>420 \mathrm{~nm}$ filter) in TEA/MeOH/water mixture with $3 \mathrm{wt} \% \mathrm{Pt}$, the TEBN11 was recovered and the reaction solution was replaced between runs.

found to be similar for TE11, TEB11 and TEBN11 (Fig. S66 and Table S12†).

To further investigate the photocatalytic performance, kinetic hydrogen evolution experiments were carried out under visible light irradiation (300 W Xe light source, $\lambda>420 \mathrm{~nm}$ filter). A sacrificial hydrogen production rate of $1894 \mu \mathrm{mol} \mathrm{g}^{-1}$ $\mathrm{h}^{-1}$ was determined for TEBN11 in TEA/MeOH/water mixtures loaded with platinum, which was nearly twice as high as for TE11 (1080 $\mu \mathrm{mol} \mathrm{g}^{-1} \mathrm{~h}^{-1}$ ), while the HER rate of TEB11 (1186 $\mu \mathrm{mol} \mathrm{g}^{-1} \mathrm{~h}^{-1}$ ) was only slightly increased compare with TE11 (Fig. 4c and Table S10 $\dagger$ ). The materials were found to contain similar amounts of platinum of approximately $1 \mathrm{wt} \%$ (Table $\left.\mathrm{S} 11^{\dagger}\right)$. All three materials are also active without additional platinum, in this case residual palladium from the synthesis facilitates the proton reduction reaction (Table S10 †). ${ }^{\mathbf{1 2 , 4 2}}$

The higher photocatalytic performance of TEBN11 compared to TEB11 and TE11 seems to originate from its deeper IP and red-shifted absorption onset allowing for enhanced light absorption. This seems to be much more important than the accessible surface area in this case, which is different to what was observed in a previous study. ${ }^{\mathbf{1 2}}$

Photocurrent and impedance measurements (Fig. S67†) also showed that TEBN11 had a larger photo-response current and smaller resistance. In addition, the photocatalytic activity had no obvious decrease over 25 hours (Fig. 4d) and the morphology also did not change (Fig. S68 $\dagger$ ). PXRD and FT-IR results (Fig. S69 and $\mathrm{S} 70 \dagger$ ) before and after the photocatalytic experiments were nearly the same, which indicating that TEBN11 has good photocatalytic stability. The external quantum efficiency (EQE) was measured at different wavelength to evaluate the HER performance, the EQE value of TEBN11 was $2.7 \%$ at $420 \mathrm{~nm}$, which is higher than TEB11 $(1.6 \%$ at $420 \mathrm{~nm})$ and TE11 $(1.6 \%$ at 420 $\mathrm{nm}$ ), and also relatively high compared to some organic polymer catalysts reported, such as covalent triazine-based framework (CTF-2, $1.6 \%$ at $420 \mathrm{~nm}),{ }^{43}$ cyano-substituted carbon-linked framework (OB-POP-3, 2.0\% at $420 \mathrm{~nm}$ ), ${ }^{44}$ and diacetylene functionalized COF (TP-BDDA, $1.3 \%$ at $420 \mathrm{~nm}$ ), ${ }^{36}$ although lower than other dibenzo $[b, d]$ thiophene sulfone copolymers (P7, 7.2\% at $420 \mathrm{~nm},{ }^{45} \mathrm{P} 10,11.6 \%$ at $420 \mathrm{~nm}$ (ref. 46) and P64, 20.7\% at $420 \mathrm{~nm}$ (ref. 13)) (Table S13†). The EQEs determined at different wavelengths of TEBN11 broadly follow the absorption profile (Fig. S71 $\dagger$ ), as expected from a photocatalytic process. ${ }^{12}$

\section{Conclusions}

In summary, 24 acetylene-linked organic polymers were synthesized via Sonogashira poly-condensation and used as photocatalysts for sacrificial hydrogen production from water under visible illumination. Using a high-throughput workflow, photocatalyst TE11, a co-polymer of 1,3,5-triethynylbenzene and dibenzo $[b, d]$ thiophene sulfone, was identified as the bestperforming material with a sacrificial hydrogen evolution rate of $1811.0 \mu \mathrm{mol} \mathrm{g}^{-1} \mathrm{~h}^{-1}$. We further optimized the structure of polymer of TE11 by increasing the size of the core and adding a triazine ring. This resulted in a further increase in hydrogen production rate under visible light illumination from $1080 \mu \mathrm{mol}$ $\mathrm{g}^{-1} \mathrm{~h}^{-1}$ for TE11 to $1894 \mu \mathrm{mol} \mathrm{g}{ }^{-1} \mathrm{~h}^{-1}$ for TEBN11 with an EQE of $2.7 \%$ at $420 \mathrm{~nm}$. The material was found to be stable under irradiation for 25 hours, which demonstrating the potential as robust organic photocatalysts for hydrogen production.

\section{Experimental section}

\section{Materials}

All reagents were obtained from Sigma-Aldrich, Fluorochem, TCI, Alfa Aesar and used as received. 1,3,5-Tris-(4-ethynylphenyl)-benzene, ${ }^{47} \quad 2,4,6$-tris[(4-ethynyl)phenyl]-1,3,5-triazine, ${ }^{48}$ were synthesized using reported literature procedures.

\section{Characterizations}

The absorption spectra of the polymers were recorded on a Cary 5000 UV-visible-NIR spectrophotometer as powders. Transmission FT-IR spectra were obtained with an attenuated total reflectance (ATR) method on a Bruker Tensor-27 spectrometer at room temperature. Photoluminescence spectra were performed on a Shimadzu RF-5301PC fluorescence spectrometer. Time-correlated single photon counting (TCSPC) experiments were measured on an Edinburgh Instruments LS980-D2S2-STM spectrometer (EPL-375 diode, $\lambda=371 \mathrm{~nm}$ ). The instrument response of the TCSPC spectrometer was measured with colloidal silica (LUDOX HS-40, Sigma-Aldrich) at the excitation wavelength. Decay times were fitted in the FAST software using three decay exponents. Thermogravimetric analysis was performed by heating samples under $\mathrm{N}_{2}$ in open platinum pans from 25 to $800{ }^{\circ} \mathrm{C}$ at $10{ }^{\circ} \mathrm{C} \mathrm{min}^{-1}$ on an EXSTAR6000 instrument. PXRD measurements were performed on a Panalytical Empyrean diffractometer with a $\mathrm{Cu}$ X-ray source. Static light scattering measurements were performed on a Malvern 
Mastersizer 3000 Particle Sizer at a laser obscuration of $5-10 \%$. Particle sizes were fitted according to the Mie theory with the Malvern 'General Purpose' analysis model. Transmittance of high-throughput samples was measured on a Formulaction S.A.S. Turbiscan AGS system with an $880 \mathrm{~nm}$ NIR diode and a detector at $180^{\circ}$ (relative to the light source) in a cylindrical glass cell. Surface areas were tested on Micromeritics 2420 instrument at a temperature of $77 \mathrm{~K}$. Before analysis, polymer samples were degassed offline at $110{ }^{\circ} \mathrm{C}$ for 15 hours under dynamic vacuum ( $10^{-5}$ bar). CHNS-O Analyzer was measured using standard microanalytical procedures. Palladium, platinum and copper contents were determined using ICP-OES Agilent 5110 equipped with a collision/reaction cell after a microwave digest of the materials in nitric acid (67-69\%, trace metal analysis grade) in a microwave. Water contact angles were measured using pressed pellets and a drop-shape analysis apparatus (Krüss DSA100) with the Young-Laplace fitting method. The morphology of the polymer particles was studied using a Hitachi S4800 SEM. X-Ray photoelectron spectroscopy (XPS) measurement were performed on a Thermo Fisher ESCALAB 250Xi instrument. The Raman measurements were performed on an inVia Reflex Qontor Confocal Raman microscope upon excitation of $785 \mathrm{~nm}$ laser. ${ }^{13} \mathrm{C}$ Magic-angle spinning measurements were carried out at $100.63 \mathrm{MHz}$ using a Bruker Avance III HD spectrometer and $4 \mathrm{~mm}$ (rotor o.d.) probe. Spectra were acquired at a spin rate of $10 \mathrm{kHz}$. Crosspolarisation (CP) spectra were recorded with TOSS spinning sideband suppression, $4 \mathrm{~ms}$ contact time and with a recycle delay of $4 \mathrm{~s}$. Carbon spectral referencing is relative to neat tetramethylsilane, carried out by setting the high frequency signal from an external sample of adamantane to $38.5 \mathrm{ppm}$.

\section{Polymer synthesis procedure}

General procedure for the Sonogashira polycondensation: in a glovebox, a glass vial was charged with the monomers, $\mathrm{Pd}\left(\mathrm{PPh}_{3}\right)_{2} \mathrm{Cl}_{2}$, CuI, triphenylphosphine, anhydrous $\mathrm{N}, \mathrm{N}$-dimethylformamide and triethylamine, and then sealed with a silicone septum. The sealed vials were taken out of the glovebox, inserted in a sand bath preheated to $100{ }^{\circ} \mathrm{C}$ and kept at this temperature for 2 days. After cooling to room temperature, the mixture was quenched by addition of methanol, and the solids were filtered off. Further purification was carried out by Soxhlet extraction with methanol and chloroform. The final product was dried in the vacuum oven at $80{ }^{\circ} \mathrm{C}$ overnight. See the $\mathrm{ESI}^{\dagger}$ for detail results of all polymers.

\section{High-throughput photocatalytic hydrogen evolution experiments}

High-throughput screening experiments were carried out using an automatic platform. For this, a sample vial $(10 \mathrm{~mL})$ was charged with $5 \mathrm{mg}$ of polymer powders and $\mathrm{H}_{2} \mathrm{PtCl}_{6}$ solution $(0.01 \mathrm{~mL}, 3 \mathrm{wt} \%$ in water), then all vials along with degassed jars of triethylamine, methanol, and water were transferred to the Chemspeed Accelerator SWING and purged with nitrogen for 6 hours. After that, the liquid transfer head was used to transfer liquids (trimethylamine/methanol/water = $1: 1: 1$; total volume $=5 \mathrm{~mL}$ ) form the jars to the vials automatically under inert conditions, then the vials were capped with the capper/ crimper tool. The sealed vials were subsequently taken out and transferred to an ultrasonic bath to finely disperse polymers by ultrasonication for 10 minutes. Photocatalytic hydrogen evolution experiments were performed on an Oriel Solar Simulator 94123A with an output of 1.0 Sun (Class AAA, $1440 \mathrm{~W}$ Xe lamp, $12 \times 12 \mathrm{in}$.). After 2 hours, the amount of hydrogen evolved was determined on an Agilent HS-GC (7890B). Control experiments of mixtures of trimethylamine/methanol/ water or trimethylamine/methanol/water $/ \mathrm{H}_{2} \mathrm{PtCl}_{6}$ showed that no hydrogen was produced in the absence of a photocatalyst.

\section{Kinetic photocatalytic hydrogen evolution measurements}

A quartz reaction flask was charge with $25 \mathrm{mg}$ polymer and $25 \mathrm{~mL}$ mixtures of water/triethylamine/methanol =1:1:1 and $0.02 \mathrm{~mL} \mathrm{H}_{2} \mathrm{PtCl}_{6}$ solution (8 wt\% in water), the flask was sealed with a rubber stopper. After ultrasonication for 10 minutes, the well-dispersed suspension was degassed by bubbling with $\mathrm{N}_{2}$ for 30 minutes before illuminating with a $300 \mathrm{~W}$ Newport Xe light source with a filter $(\lambda>420 \mathrm{~nm})$. The concentration of hydrogen was determined by a Bruker 450 GC gas chromatograph equipped with TCD detector. For longer-term stability experiments, after illumination for 5 hours, the polymer was recovered through filtration, and after drying, $25 \mathrm{~mL}$ mixtures of water/triethylamine/methanol $=1: 1: 1$ were added again for the next run. For external quantum efficiency (EQE) measurements, experiments were performed under a light-emitting diode irradiation $(\lambda=420,490,700 \mathrm{~nm})$, and the EQE was estimated using the following formula:

$$
\mathrm{EQE} \%=\frac{2 \times \text { number of evolved } \mathrm{H}_{2} \text { molecules }}{\text { number of incident photons }} \times 100 \%
$$

\section{Electrochemical measurements}

Electrochemical experiments were performed on the BioLogic SP200 workstation. The transient photocurrent responses $(I-t)$ and electrochemical impedance spectra (EIS) of samples were investigated in a three-electrode system (FTO, Pt plate, and Ag/ $\mathrm{AgCl}$ as working, counter, and reference electrode, respectively) using a $300 \mathrm{~W}$ Xe light source (Newport). The electrolyte was $0.5 \mathrm{M} \mathrm{Na} \mathrm{SO}_{4}$ aqueous solution and was degassed for 30 minutes by $\mathrm{N}_{2}$ at room temperature before the measurement. The working electrode was prepared as follows: $2 \mathrm{mg}$ of the photocatalyst was ultrasonicated with $10 \mu \mathrm{L}$ Nafion (5 wt $\%$ ) aqueous solution and $100 \mu \mathrm{L}$ ethanol giving a slurry. The slurry was then coated onto FTO glass electrodes with an active area of $1 \mathrm{~cm}^{2}$. The applied bias for intermittent photocurrent intensity measurement was $0.6 \mathrm{~V}$ vs. $\mathrm{Ag} / \mathrm{AgCl}$. The EIS spectra were determined by applying a $10 \mathrm{mV}$ AC signal over the frequency range of $100 \mathrm{kHz}$ to $10 \mathrm{mHz}$ at a DC bias of $0.6 \mathrm{~V} \mathrm{vs.} \mathrm{Ag} / \mathrm{AgCl}$.

\section{Density functional theory (DFT) calculations}

DFT calculations are helpful for computationally screening of candidate polymer photocatalysts and to gain a deep 
understanding of the structure and property relationships. For the DFT calculations, the TE and DE polymers were represented by finite (i.e., nonperiodic) oligomeric models; linear oligomers of composition $(\mathrm{L}(\mathrm{DE}))_{6}$ in the case of $\mathrm{DE}$ polymers and a $\mathrm{TE}$ centered $(\mathrm{TE})(\mathrm{L}(\mathrm{TE}))_{3}$ oligomers in the case of the TE polymers (Fig. S48†). The starting structures of the oligomers were constructed with the program STK. ${ }^{49}$ Having identified the representative conformer of each oligomer, we proceeded to optimize its geometry using density functional theory (DFT). To calculate the adiabatic ionization potential (IP) and adiabatic electron affinity (EA) of the oligomer, the geometries of the radical cation and radical anion forms of the representative conformer were likewise optimized using DFT. The excitation spectrum of the charge-neutral form of the representative conformer was calculated using time-dependent DFT (TD-DFT).

The DFT and TDDFT calculations were performed with the program Turbomole, version 6.5. The B3LYP exchange-correlation functional ${ }^{50,51}$ was used in combination with the DZP basis set. ${ }^{52,53}$ The effects of aqueous solvation were included via the conductor-like screening model (COSMO). ${ }^{54,55}$ At all times, the energies and gradients were corrected for dispersion effects with the D3 semiempirical dispersion correction scheme of Grimme and coworkers. ${ }^{56}$

\section{Conflicts of interest}

There are no conflicts to declare.

\section{Acknowledgements}

We thank the Engineering and Physical Sciences Research Council (EPSRC) for financial support under Grant EP/N004884/ 1. L. L. thanks the China Scholarship Council for a PhD studentship. R. S. S. thanks the University of Strathclyde for financial support through The Strathclyde Chancellor's Fellowship Scheme.

\section{Notes and references}

1 B. A. Pinaud, J. D. Benck, L. C. Seitz, A. J. Forman, Z. Chen, T. G. Deutsch, B. D. James, K. N. Baum, G. N. Baum, S. Ardo, H. Wang, E. Miller and T. F. Jaramillo, Energy Environ. Sci., 2013, 6, 1983-2002.

2 C. Jiang, S. J. A. Moniz, A. Wang, T. Zhang and J. Tang, Chem. Soc. Rev., 2017, 46, 4645-4660.

3 T. Hisatomi and K. Domen, Nat. Catal., 2019, 2, 387-399.

4 Y. Miseki and K. Sayama, Adv. Energy Mater., 2019, 9, 1801294.

5 A. Fujishima and K. Honda, Nature, 1972, 238, 37-38.

6 S. Yanagida, A. Kabumoto, K. Mizumoto, C. Pac and K. Yoshino, J. Chem. Soc., Chem. Commun., 1985, 8, 474-475.

7 T. Shibata, A. Kabumoto, T. Shiragami, O. Ishitani, C. Pac and S. Yanagida, J. Phys. Chem., 1990, 94, 2068-2076.

8 T. Zhang, G. Xing, W. Chen and L. Chen, Mater. Chem. Front., 2020, 4, 332-353.
9 X. Wang, K. Maeda, A. Thomas, K. Takanabe, G. Xin, J. M. Carlsson, K. Domen and M. Antonietti, Nat. Mater., 2009, 8, 76-80.

10 J. Kosco, M. Bidwell, H. Cha, T. Martin, C. T. Howells, M. Sachs, D. H. Anjum, S. Gonzalez Lopez, L. Zou, A. Wadsworth, W. Zhang, L. Zhang, J. Tellam, R. Sougrat, F. Laquai, D. M. DeLongchamp, J. R. Durrant and I. McCulloch, Nat. Mater., 2020, 19, 559-565.

11 D. J. Woods, S. A. J. Hillman, D. Pearce, L. Wilbraham, L. Q. Flagg, W. Duffy, I. McCulloch, J. R. Durrant, A. A. Y. Guilbert, M. A. Zwijnenburg, R. S. Sprick, J. Nelson and A. I. Cooper, Energy Environ. Sci., 2020, 13, 1843-1855.

12 R. S. Sprick, Y. Bai, A. A. Y. Guilbert, M. Zbiri, C. M. Aitchison, L. Wilbraham, Y. Yan, D. J. Woods, M. A. Zwijnenburg and A. I. Cooper, Chem. Mater., 2019, 31, 305-313.

13 Y. Bai, L. Wilbraham, B. J. Slater, M. A. Zwijnenburg, R. S. Sprick and A. I. Cooper, J. Am. Chem. Soc., 2019, 141, 9063-9071.

14 L. Wang, X. Zheng, L. Chen, Y. Xiong and H. Xu, Angew. Chem., Int. Ed., 2018, 57, 3454-3458.

15 C. Zhao, Z. Chen, R. Shi, X. Yang and T. Zhang, Adv. Mater., 2020, 32, 1907296.

16 T. Banerjee, K. Gottschling, G. Savasci, C. Ochsenfeld and B. V. Lotsch, ACS Energy Lett., 2018, 3, 400-409.

17 X. Wang, L. Chen, S. Y. Chong, M. A. Little, Y. Wu, W.-H. Zhu, R. Clowes, Y. Yan, M. A. Zwijnenburg, R. S. Sprick and A. I. Cooper, Nat. Chem., 2018, 10, 11801189.

18 J. Li, X. Jing, Q. Li, S. Li, X. Gao, X. Feng and B. Wang, Chem. Soc. Rev., 2020, 49, 3565-3604.

19 Y. Wan, L. Wang, H. Xu, X. Wu and J. Yang, J. Am. Chem. Soc., 2020, 142, 4508-4516.

20 W. Chen, L. Wang, D. Mo, F. He, Z. Wen, X. Wu, H. Xu and L. Chen, Angew. Chem., Int. Ed., 2020, 59, 16902-16909.

21 C. M. Aitchison, C. M. Kane, D. P. McMahon, P. R. Spackman, A. Pulido, X. Wang, L. Wilbraham, L. Chen, R. Clowes, M. A. Zwijnenburg, R. S. Sprick, M. A. Little, G. M. Day and A. I. Cooper, J. Mater. Chem. A, 2020, 8, 7158-7170.

22 K. Schwinghammer, S. Hug, M. B. Mesch, J. Senker and B. V. Lotsch, Energy Environ. Sci., 2015, 8, 3345-3353.

23 L. Guo, Y. Niu, H. Xu, Q. Li, S. Razzaque, Q. Huang, S. Jin and B. Tan, J. Mater. Chem. A, 2018, 6, 19775-19781.

24 J. Xie, S. A. Shevlin, Q. Ruan, S. J. A. Moniz, Y. Liu, X. Liu, Y. Li, C. C. Lau, Z. X. Guo and J. Tang, Energy Environ. Sci., 2018, 11, 1617-1624.

25 C. B. Meier, R. Clowes, E. Berardo, K. E. Jelfs, M. A. Zwijnenburg, R. S. Sprick and A. I. Cooper, Chem. Mater., 2019, 31, 8830-8838.

26 J. Yu, X. Sun, X. Xu, C. Zhang and X. He, Appl. Catal., B, 2019, 257, 117935.

27 R. S. Sprick, Z. Chen, A. J. Cowan, Y. Bai, C. M. Aitchison, Y. Fang, M. A. Zwijnenburg, A. I. Cooper and X. Wang, Angew. Chem., Int. Ed., 2020, 59, 2-8. 
28 Y. Bai, K. Nakagawa, A. J. Cowan, C. M. Aitchison, Y. Yamaguchi, M. A. Zwijnenburg, A. Kudo, R. S. Sprick and A. I. Cooper, J. Mater. Chem. A, 2020, 8, 16283-16290.

29 L. Lin, Z. Lin, J. Zhang, X. Cai, W. Lin, Z. Yu and X. Wang, Nat. Catal., 2020, 3, 649-655.

30 Z. Qin, Z. Huang, M. Wang, D. Liu, Y. Chen and L. Guo, Appl. Catal., B, 2020, 261, 118211.

31 G. Zhang, Z.-A. Lan and X. Wang, Angew. Chem., Int. Ed., 2016, 55, 15712-15727.

32 M. Rahman, H. Tian and T. Edvinsson, Angew. Chem., Int. Ed., 2020, 59, 2-18.

33 H. J. Sun, I. H. Oner, T. Wang, T. Zhang, O. Selyshchev, C. Neumann, Y. B. Fu, Z. Q. Liao, S. Q. Xu, Y. Hou, A. Turchanin, D. R. T. Zahn, E. Zschech, I. M. Weidinger, J. Zhang and X. L. Feng, Angew. Chem., Int. Ed., 2019, 58, 10368-10374.

34 X.-H. Zhang, X.-P. Wang, J. Xiao, S.-Y. Wang, D.-K. Huang, X. Ding, Y.-G. Xiang and H. Chen, J. Catal., 2017, 350, 64-71.

35 T. Zhang, Y. Hou, V. Dzhagan, Z. Q. Liao, G. L. Chai, M. Loffler, D. Olianas, A. Milani, S. Q. Xu, M. Tommasini, D. R. T. Zahn, Z. K. Zheng, E. Zschech, R. Jordan and X. L. Feng, Nat. Commun., 2018, 9, 1140.

36 P. Pachfule, A. Acharjya, J. Roeser, T. Langenhahn, M. Schwarze, R. Schomäcker, A. Thomas and J. Schmidt, J. Am. Chem. Soc., 2018, 140, 1423-1427.

37 S. Ghosh, N. A. Kouamé, L. Ramos, S. Remita, A. Dazzi, A. Deniset-Besseau, P. Beaunier, F. Goubard, P.-H. Aubert and H. Remita, Nat. Mater., 2015, 14, 505-511.

38 L. Wang, Y. Wan, Y. Ding, S. Wu, Y. Zhang, X. Zhang, G. Zhang, Y. Xiong, X. Wu, J. Yang and H. Xu, Adv. Mater., 2017, 29, 1702428.

39 X. Wang, B. Chen, W. Dong, X. Zhang, Z. Li, Y. Xiang and H. Chen, Macromol. Rapid Commun., 2019, 40, 1800494.

40 P. Guiglion, C. Butchosa and M. A. Zwijnenburg, J. Mater. Chem. A, 2014, 2, 11996-12004.

41 Z. Wu, J. Wang, K. Xia, W. Lei, X. Liu and D. Wang, J. Mater. Chem. A, 2018, 6, 616-622.
42 M. Sachs, H. Cha, J. Kosco, C. M. Aitchison, L. Francàs, S. Corby, C.-L. Chiang, A. A. Wilson, R. Godin, A. FaheyWilliams, A. I. Cooper, R. S. Sprick, I. McCulloch and J. R. Durrant, J. Am. Chem. Soc., 2020, 142, 14574-14587.

43 C. B. Meier, R. S. Sprick, A. Monti, P. Guiglion, J.-S. M. Lee, M. A. Zwijnenburg and A. I. Cooper, Polymer, 2017, 126, 283-290.

44 S. Bi, Z.-A. Lan, S. Paasch, W. Zhang, Y. He, C. Zhang, F. Liu, D. Wu, X. Zhuang, E. Brunner, X. Wang and F. Zhang, Adv. Funct. Mater., 2017, 27, 1703146.

45 R. S. Sprick, B. Bonillo, R. Clowes, P. Guiglion, N. J. Brownbill, B. J. Slater, F. Blanc, M. A. Zwijnenburg, D. J. Adams and A. I. Cooper, Angew. Chem., Int. Ed., 2016, 55, 1792-1796.

46 M. Sachs, R. S. Sprick, D. Pearce, S. A. J. Hillman, A. Monti, A. A. Y. Guilbert, N. J. Brownbill, S. Dimitrov, X. Shi, F. Blanc, M. A. Zwijnenburg, J. Nelson, J. R. Durrant and A. I. Cooper, Nat. Commun., 2018, 9, 4968.

47 X. Wang, S.-m. Lu, J. Li, Y. Liu and C. Li, Catal. Sci. Technol., 2015, 5, 2585-2589.

48 D. Schwarz, Y. S. Kochergin, A. Acharjya, A. Ichangi, M. V. Opanasenko, J. Čejka, U. Lappan, P. Arki, J. He, J. Schmidt, P. Nachtigall, A. Thomas, J. Tarábek and M. J. Bojdys, Chem.-Eur. J., 2017, 23, 13023-13027.

49 L. Turcani, E. Berardo and K. E. Jelfs, J. Comput. Chem., 2018, 39, 1931-1942.

50 A. D. Becke, J. Chem. Phys., 1993, 98, 5648-5652.

51 P. J. Stephens, F. J. Devlin, C. F. Chabalowski and M. J. Frisch, J. Phys. Chem., 1994, 98, 11623-11627.

52 A. Schäfer, H. Horn and R. Ahlrichs, J. Chem. Phys., 1992, 97, 2571-2577.

53 J. Gauss, J. Chem. Phys., 1993, 99, 3629-3643.

54 A. Klamt and G. Schüürmann, J. Chem. Soc., Perkin Trans. 2, 1993, 2, 799-805.

55 A. Schäfer, A. Klamt, D. Sattel, J. C. W. Lohrenz and F. Eckert, Phys. Chem. Chem. Phys., 2000, 2, 2187-2193.

56 S. Grimme, J. Antony, S. Ehrlich and H. Krieg, J. Chem. Phys., 2010, 132, 154104. 